\title{
MACGYVERS, MEDEAS, AND BIONIC WOMEN
}

\author{
PATTERNS OF INSTRUCTOR RESPONSE \\ TO NEGATIVE FEEDBACK
}

Allison P. Boye, Suzanne Tapp, Texas Technological University

Few studies have examined instructor responses to negative feedback and their interplay with gender, but faculty developers must be cognizant of and sensitive to the needs of the instructors with whom they work. This chapter identifies six general patterns of response among male and female instructors to negative feedback from students and consultants, based on survey results, interviews, and observations. A combination of empathy, resources, and time is the key to understanding and responding to those patterns and meeting the needs of individual instructors. Further, comparisons across gender reveal interesting differences related to language use, internalization versus externalization of feedback, and holistic versus specific approaches to reflective teaching.

We have all observed patterns of behavior in our colleagues, students, and faculty members such as common ways of speaking or dressing, patterns of anger, and similar responses to stress or excitement. As faculty developers, we have identified several response patterns from instructors as they reflect on negative feedback about their teaching. As such, we began to take note of how instructors, both male and female, react to the consultation process and negative feedback. Some instructors meet the feedback with flatness or indifference, while others adopt an emotional progression from devastation and anger to acceptance and action. Although instructors of both genders demonstrated some commonalities, they also demonstrated some very distinct differences in how they perceive and react to student feedback and the consultation process in general. 
According to Diamond (2002), faculty developers must judge how sensitive an instructor will be to receiving student and consultant commentary. This becomes complicated when the dynamics of gender and potential conflict come into play. Our primary questions here are:

- How do instructors perceive the feedback they receive from students and consultants?

- How do instructors of both genders respond to feedback from students or consultants?

- How can faculty developers adjust their practice to respond to these patterns of response from instructors?

\section{Context}

Little research has been conducted on instructor responses to feedback across gender, particularly in relation to faculty development practice; much research, however, has investigated the reliability of student evaluations along gender lines, as well as faculty responses to stress. Much of the research conducted in the area of formal student evaluations of instructors reveals mixed results in regard to gender. Many, among them Centra and Gaubatz (2000) and Theall and Franklin (2001), report that, despite naysayers, standard student evaluations are generally reliable and indicate no strong gender-based bias; more specifically, students "do not favor instructors on the basis of gender alone" (Theall \& Franklin, 2001, p. 50).

However, other studies (Andersen \& Miller, 1997; Bachen, McLoughlin, \& Garcia, 1999; Basow, 2000; Meyers, Bender, Hill, \& Thomas, 2006; Sprague \& Massoni, 2005) show that students often maintain different behavioral expectations of male and female instructors, usually related to gender-based stereotypes. For instance, some students expect female instructors to exhibit nurturing qualities, and they may penalize those who do not exhibit those qualities in student-teacher interactions. Franklin and Theall (1994); Laube, Massoni, Sprague, and Ferber (2007); and Theall (2005) call attention to other gender-based factors-such as how departments assign teaching responsibilities or how students interpret instructors' delivery-that can influence student evaluation of or behavior toward female instructors, as well as instructors' experiences in the classroom, which are often not easily detectable on traditional evaluation scales.

Regarding change and reaction to student evaluations, Schmelkin, Spencer, and Gellman (1997) show that faculty appear to view student 
feedback differentially. Instructors were not necessarily resistant to student feedback, as anticipated, yet they viewed feedback on interaction as most valuable while paying less heed to other elements. Nasser and Fresko (2002) indicate that few faculty reported changing instruction significantly as a result of student evaluations. However, studies by Piccinin (1999) and Piccinin, Cristi, and McCoy (1999) report that focused individual teaching consultations, including direct student feedback elicited privately by a consultant, are effective in influencing change and improving the quality of consultees' teaching. Interestingly, Roberts and NolenHoeksema (1989) find that males and females exhibit subtle differences in their reactions to performance feedback. Their study suggests that negative and positive feedback more readily influences women's selfassessment of their own abilities.

\section{Our Investigation}

We surveyed instructors at our institution who participated in the smallgroup instructor diagnostic (SGID) process over the past three years (solicited $n=84$, respondent $n=41$ ). Our sample included male and female graduate teaching assistants, lecturers, and tenure-track and tenured faculty from all disciplines.

The survey gathered demographic data from the instructors such as gender, rank, and teaching experience, as well as their reflections on the SGID experience and responses to feedback. The survey used both openended and Likert scale questions, such as: How did you feel about your teaching after receiving the SGID feedback? How did you feel toward your students after receiving the SGID feedback? How often, if at all, did your students express frustration or satisfaction with the class before or after the SGID? How satisfied were you with the helpfulness of your consultant in evaluating students' feedback?

As part of our investigation, we also conducted individual interviews $(n=7)$ with male and female instructors from a variety of disciplines and ranks who initiated contact with us on the basis of their experiences with student evaluations, classroom incivility, sheer frustration, or simple desire for feedback. We included these faculty as well as survey respondents (described below), although the survey responses remained anonymous. To preserve confidentiality, we have also changed all names included in this chapter. Although the quantitative survey data did not show significant differences between male and female responses, the qualitative data and interviews revealed differences in how male and female instructors responded to negative feedback. 


\section{Our Discoveries}

Some general patterns of response from male and female instructors emerged from the data that call to mind memorable cultural icons (summarized in Table 8.1). These patterns fall into three general categories: emotional responses ("Medea" and "Mr. Inconceivable"), detached responses ("Scarlett" and "Nero"), and action-oriented responses ("Bionic Woman" and "MacGyver"). These icons or archetypes may seem like light-hearted jokes or jabs, or even faculty bashing to amuse ourselves and our faculty development peers. However, at their core they could help faculty developers anticipate instructor responses to the consultation process and interact more effectively with individuals. We are not seeking to pigeonhole or offend, but rather to offer some unforgettable representations of possible behaviors. As with any imposed category, the lines between some of these patterns are often blurred, mutable, and not even always gender-specific. Regardless of inevitable overlap, recognizing the paradigms in some form, whether male or female, may help faculty developers prepare for and facilitate consultations.

\section{Emotional Responses}

Medea: "I felt that some of the comments were a little too critical. It seemed that some students were whining because they had to read and do homework for a college class." The first pattern we identified in some female instructors is the Medea, the protagonist in the classic story of a betrayed woman's revenge. The behavior we associate with this archetype belongs to instructors who get angry at the negative feedback, sometimes blaming their students for classroom struggles. We also include in this category instructors who demonstrate utter despair in response to feedback, who lament the work they have done as teachers and feel betrayed by the students to whom they have revealed their souls. They do not necessarily lash out at their students or consultants, but like those instructors who get angry they bring with them deep pain. Certainly this reaction is understandable given the amount of work many faculty and teaching assistants pour into their teaching.

One example of an instructor whose response fit into this pattern was Jennifer, a graduate instructor from the College of Education who requested our services near the end of a long and contentious semester with her students. She initiated contact with us via a long email in which she adopted a "victim's stance" in referring to her students, already exuding a great deal of anger toward them and blaming them for the majority, if not all, of the problems she was experiencing as their instructor. 


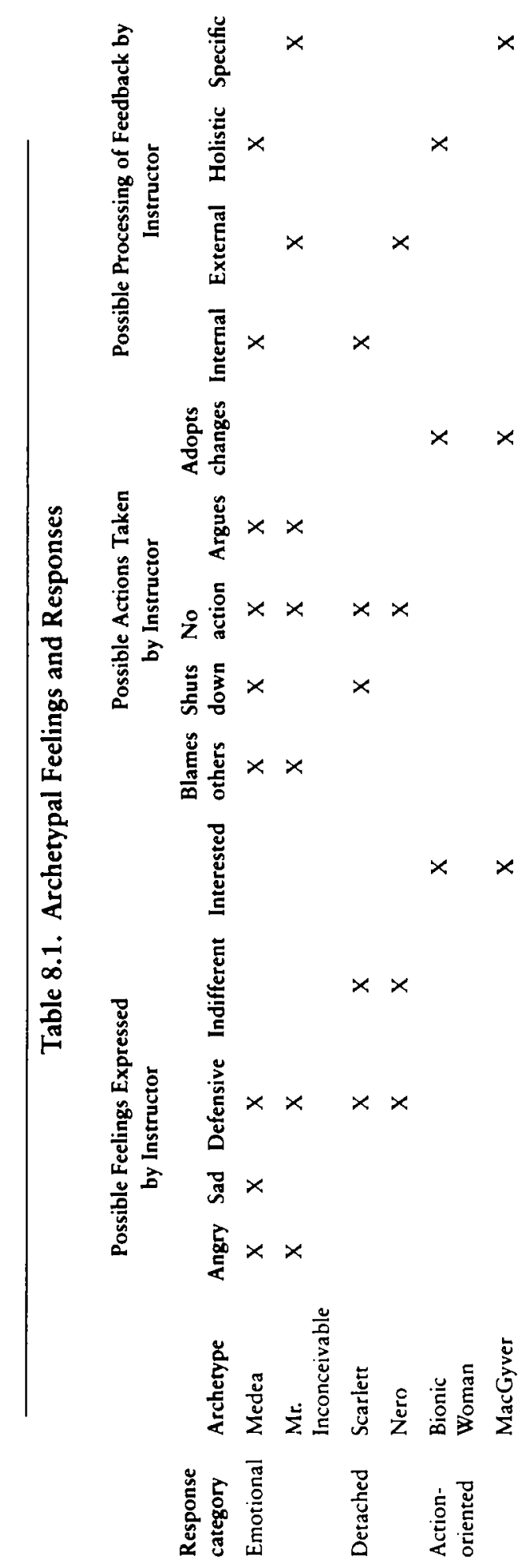


Student complaints ranged from grading practices to course content. During her SGID, student descriptions of her erratic classroom behavior and their extreme malcontent alarmed us, and our initial expectations were confirmed when Jennifer displayed great anger and then sadness during the consultation, even pounding her fist on the table and eventually crying and laying her head on her hands.

Another initial Medea response came from Erin, an assistant professor in human development and family studies, whose negative student feedback took her by surprise. Having received a significant amount of pedagogical training, she was shocked and dismayed to learn that her students were dissatisfied with her expectations. She too responded with anger and sadness during her consultation, shedding tears and raising her voice, ultimately deciding to conduct her own SGID, which questioned her students' role in and commitment to the class.

Yolanda, a full professor from human sciences with an impressive research agenda, called on us after years of negative student evaluations that she described as "really hurtful." Unlike Jennifer, whose primary response was anger, Yolanda initially expressed deep sadness at her students' responses, remarking, "I get so discouraged and feel I should just not teach" (personal communication, January 30, 2007). Similarly, Denise, another Medea, expressed to us, "They [student comments] are just so mean. Why can't they see how much I invest in my teaching?" (personal communication, October 13, 2008).

Several comments from our survey also appear to reflect this pattern. For instance, one respondent wrote, "[I felt $]$ somewhat exasperated ... they [the students] were commenting on things that I had no control over." Another respondent commented, "I was a little hurt by a few of the comments," while another revealed, "It was insightful but slightly disappointing because the feedback I'd get from them regarding my teaching was generally positive and the SGID showed more negative feedback from them-something I wasn't really expecting and which made me question the disparity." These instructors clearly found the feedback to be meaningful and were processing it in a very personal way.

Mr. Inconceivable: "I was pretty happy with [my students'] responses, but had to wonder how honest many of them were." One response pattern we identified in some male instructors harkens back to the memorable Sicilian kidnapper Vizzini from the now-classic film The Princess Bride, who proclaims his own brilliance with the remark, "Let me put it this way. Have you ever heard of Plato? Aristotle? Socrates? . . Morons!" Like this well-loved character who met every revelation or contention from others with the unforgettable declaration "Inconceivable!" these 
instructors often bring palpable skepticism to their consultations and might meet negative feedback with argumentation.

Jeff, a young philosophy instructor, was the perfect example of the $\mathrm{Mr}$. Inconceivable response. He requested multiple classroom observations over several semesters, and during several consultations a number of consultants encouraged him to try harder to connect with his students and engage in faculty immediacy (Kearney \& Plax, 1992; Meyers, 2003; Pogue \& AhYun, 2006) to increase his students' motivation and participation. Despite the extremely small size of his two discussion sections (each ten to fifteen students), Jeff argued that he had too many students to learn and use their names during class. It took a great deal of consultation time and many references to push Jeff to begin to realize the importance-and feasibility - of learning his students' names.

Donald, a history instructor, embodied another example of devoted skepticism. His consultant initially observed a meeting of Donald's introductory history course, during which he presented dozens of PowerPoint slides during the short fifty-minute class. Later, his consultant advised him to consider incorporating simple active learning strategies and class discussion to augment his enthusiastic lectures and get his students more engaged with the material. At the outset, Donald vigorously questioned the practicability of these suggestions, voicing the classic concern that they would interfere with his ability to "cover" the necessary course content. Even as he made attempts to apply some of the suggestions, he continued to express doubts about their effectiveness, going so far as to forward to his consultant an email from a student dropping his class: "Guess the active-learning approach is hard for her too!" (personal communication, January 22, 2008).

Our survey contained some comments that reflected this approach to feedback. "I would like to have the person conducting the SGID ask the students what they could do to improve the class," wrote one Mr. Inconceivable, who clearly questioned the validity of the students' assessments. Mr. Inconceivable instructors often enjoyed talking about their own classroom experiences but were initially skeptical in response to feedback from others.

\section{Detached Responses}

Scarlett: "I was glad for the honest feedback, but I came away from it feeling like there was no way to make all of the students happy. What one student liked, another student hated. I felt that there is no way to please all of them." The second archetype we identified in some female instructors was the Scarlett O'Hara response, the seemingly apathetic "fiddle-dee-dee" 
reaction to negative feedback. These are the instructors who may shrug their shoulders and appear noncommittal. As Scarlett says in Gone with the Wind, these instructors may seem to believe "there is no war" and don't want to be bothered by it. They'd prefer to just walk away, outwardly content to go about their business when faced with the difficulty of hearing negative feedback.

One Scarlett example was a lecturer from health, exercise, and sports sciences who contacted us regarding her teaching. Although Lauren entered her teaching career with enthusiasm, classroom incivility issues and difficulty connecting with students soon soured her experience. Clearly she was affected by the turmoil she experienced with her students and the feedback she received from them. In her own words, her description of the "blood, sweat, and tears" she put into her teaching indicated that this was indeed an emotional Medea experience for her (personal communication, October 2, 2008). However, what she perceived as "constant opposition" quickly led her to shut down, to throw up her hands in the Scarlett fashion and declare that she could never make anybody happy, no matter what she did. Lauren commented that "this has really taken a toll on me and makes me look as if I am this mad black woman with an attitude" (personal communication, February 19, 2008). Regrettably, she left teaching after a few semesters, choosing to pursue another career path.

An associate professor from chemistry also demonstrated the classic Scarlett pattern. A classroom observation revealed that students blatantly cheated on a quiz, entered and left the room throughout the class, and talked to each other with little regard for her lecture. The faculty developer also noted that the instructor lectured nonstop using PowerPoint slides crammed with text and equations that literally ran off the screen. In the follow-up consultation, the instructor's response was decidedly ambivalent; her comments were almost nonresponsive and consisted of "hmm" and "OK." Despite strong encouragement, she has made no further requests for consultations or attempts to solicit feedback.

Yet another Scarlett emerged from the English department. In spite of receiving numerous emotional comments from students over several semesters about overly time-consuming components of the class, the instructor refused to make adjustments to her syllabus or her teaching. Some of her student comments were quite thoughtful (for example: "I don't like that everyday we come to class and she just lectures. The benefit of a small class is that we can all discuss and have a more personal environment. I didn't feel like I got a chance to connect well with my peers or the works studied in this class."). Yet the instructor brushed off 
such remarks as signs of student laziness or lack of understanding (personal communication, April 7, 2006).

The survey also contained Scarlett-type responses, such as those in answer to the question, "What changes did you make to your teaching?" One Scarlett admitted, "I did consider changing some policies/scheduling, but I decided against it." Another replied, "I think most of the things that were brought up were things which really couldn't be changed at that point in the semester." These comments demonstrated the tendency to shut down in response to feedback.

Nero: "I am not sure how the SGID changed my teaching." Another response pattern we identified in male instructors reflects the mentality of Nero, who fiddled while Rome burned. When faced with negative feedback from students or faculty developers, this instructor might display a similarly indifferent or seemingly unconcerned response. Like Mr. Inconceivable, Nero may argue against the student responses or the faculty developer's observations but also convey some underlying arrogance or disinterest in struggling to process the feedback.

Ned, a knowledgeable lecturer in history, confronted critical comments from his SGID, such as, "I don't think a class that is strictly lecture works because it's boring. One gets better results when they interact with the class" and "Sometimes he can go over too much information at one time. It's hard to get all of his points down at times. It would help if he didn't squeeze in so much information at the end of class" (personal communication, October 24, 2004). These remarks mirrored suggestions from a faculty developer who had observed him in the classroom on multiple occasions and offered ways to help him slow down his rapid-fire storytelling delivery and encourage student questions. But Ned literally responded, "Interesting. What else have you got?" Repeated comments over two semesters of SGID feedback were met with flat indifference and lack of recognition of any problems with the current classroom dynamic.

Another Nero example was a graduate student from marketing, Mark, who incorporated use of blogs in his classes. Student comments from the SGID concurred in their dissatisfaction with this use of the blog as an emerging technology. As one student put it, "I am not a big fan of the class blog. It doesn't really help me learn and it's just people posting their opinions" (personal communication, February 24, 2006). Yet the instructor believed that the blog worked beautifully and achieved his goal of student engagement, despite students saying that it "was just a task to always check the blog." He continued to use blogs in all subsequent classes he taught at our university and disregarded the feedback that students were not connecting with the technology. Following a classroom 
observation, faculty developers noted that his use of a forced cold call participation strategy seemed to be counterproductive to his desire to engage students. But he ignored comments on his SGID such as, "Stop randomly calling on people. Making people look foolish doesn't promote learning-it promotes fear!" and "he should do something else to involve everyone besides calling on random people" (personal communication, February 24, 2006).

We also noticed a few aloof survey responses from male respondents that sounded like Nero responses, such as, "I believe my students were being honest and trying to help me, and their evaluations did not affect my feelings towards them" and "I really felt no differently towards my students after the SGID, compared to before the SGID, though I did appreciate their willingness to provide candid feedback." Students often perceived Nero instructors as knowledgeable but disconnected.

\section{Action-Oriented Responses}

Bionic Woman: "I think that I am a good teacher overall but I have been able to make some changes based on comments from the feedback that I think have made me better." A third response pattern we recognized in female instructors is what we like to think of as the Bionic Woman. Like Jamie Summers, who suffered a parachuting accident in the popular television show of the 1970s, these instructors, in spite of suffering the "trauma" or "injury" of negative student or consultant feedback, ultimately rebuild themselves, their teaching strategies, and their relationship with their students, and become stronger than ever. They take action based on the feedback they receive to positively reshape their classroom.

One recent Bionic Woman example on our campus was an associate professor in health, exercise, and sports science who incorporated a significant service-learning project into her course that frustrated her students one semester because of problems in communication. On receiving somewhat harsh SGID feedback, she met with her community partners and worked hard to improve communication, rather than deeming the project a disaster and calling it quits. She approached the criticism graciously, took the feedback in stride, and made some important changes to meet her students' needs.

Further, although both Yolanda and Erin likewise began the consultation process with the Medea response pattern, they eventually transformed themselves into Bionic Women. Both of them worked through the initial pain of the feedback and took action to make significant changes in their teaching approach. Erin, for instance, chose to talk to her students directly 
about their comments and solicited even more feedback from them. Through this process she realized the error in her assumptions about their abilities and motivation, and she now starts each semester by clearly explicating her expectations. Taking a quieter approach, Yolanda thoughtfully analyzed each suggestion from her consultant and the feedback from her students with slight reluctance. But eventually she warmed to the process and began incorporating new teaching strategies. Yolanda's changes met with great success; the semester following her consultations, she wrote to us in an email:

1 just received my student evaluations for Fall of 07 and almost sobbed!!! I am attaching a copy of them so that you can see how great they were!!! I am sooooooooooooooo thankful to you for helping me improve my teaching skills. I did not think I had it in me to do. You have made an incredible difference in me professionally and I want you to know how much I appreciate all the help you gave me last year. Thank you, thank you, thank you. [personal communication, January 23, 2008]

The Bionic Women in our survey wrote comments such as these: "I've learned that as a teacher, you must continually assess your performance in order to be most effective. I found myself in a 'teaching rut' and I believe that the evaluation process opened my eyes to new ideas." And "Becoming aware of areas of improvement helped me address the issues which I could work on to make the classes more worthwhile." These responses demonstrated a clear desire to engage in reflective teaching and make changes that work toward improvement.

MacGyver: "My teaching changed because I saw what works in the class so I reinforced the use of those techniques or dynamics that work. At the same time I took very seriously what did not work and tried to implement different strategies to reverse the weaknesses into strengths using recommendations from the consultants and the students." The resourceful secret agent MacGyver, the title character from the hit 1980 s television series, represents the third pattern we identified among male instructors. Just as MacGyver could solve almost any problem with duct tape, a paperclip, and his handy Swiss army knife, this kind of instructor is willing to work with student feedback and consider issues raised by consultants.

SGID feedback from an information systems and quantitative sciences class informed the instructor of a classroom dynamic he hadn't noticed before. Students commented that "it disrupts the class when the same student shows up 30-45 minutes late every class period. That student 
then asks questions about topics which were covered in detail before his very late arrival" (personal communication, October 16, 2007). The instructor obviously was familiar with the student's tardiness but did not recognize how it disturbed the other students. He met with the chronically late arriver the next day and resolved the problem. Perhaps this is why his students also volunteered that this MacGyver-style instructor "cooperates with students" and "is open to questions and to making sure that we keep learning new things" (personal communication, October 16, 2007).

A graduate student from computer science, Fred, transformed from $\mathrm{Mr}$. Inconceivable into MacGyver in a process that was recognizable only over time. Classroom observations and SGIDs with his introductory class clearly indicated that his traditional lecture-based format was not engaging his students or giving them opportunities to program and code. Fred struggled to accept these problems as he reexamined his teaching goals. Slowly he began to incorporate in-class problem solving and student-led discussion, and to invite students to show their techniques on the board. A student who took a class with him one semester and another class the next semester remarked about the change: "I have seen significant improvement in his teaching methods" (personal communication, March $20,2006)$. The faculty developers he worked with counted his MacGyverlike transition as a highlight of the year.

Instructors who fit into the MacGyver pattern wrote comments on our survey like these:

I became aware of some improvements I could do in the semester itself, so that the learning process could be enhanced. I also could see that there were areas I could do much better, in terms of idiosyncrasies and mannerisms, and overall pedagogy.

The constructive nature of the feedback helped to focus my attention on making my reaching as good as possible (rather than focusing on how bad my teaching may be now).

Becoming aware of areas of improvement helped me address the issues which I could work on to make the classes more worthwhile.

My attitude towards students and teaching has changed significantly. Before the SGID, I was not conscious of student-centered learning and engaging students actively. After the SGID, every time I get into the classroom, I ask myself, "Will this aspect of my teaching benefit srudents or not?" [personal communication, November 21, 2008]

As these comments reveal, MacGyvers are eager to improve their classroom experiences quickly and thoughtfully. 


\section{Responding to the Patterns}

Knowing these patterns can help faculty developers prepare themselves to meet the individual needs of each instructor and respond wisely to the faculty reaction to the feedback and consultation process. Finding the right combination of empathy, time, and resources is ultimately the key to an effective collaborative consultation model (Brinko, 1997) and what we have termed relational perseverance-that is, the motivation to invest appropriately in an individual faculty member. Relational perseverance is needed to effect change and represents the partnership between faculty developer and instructor as they negotiate negative feedback.

\section{Empathy}

One of our Medeas, Erin, described the significance of the consultation process by saying that the "discussion was particularly helpful because it [the feedback] was a painful experience." In describing the process of working through the student comments and understanding the years of missed connections with her students, Erin said that she was "raw and fragile" and appreciated how the faculty developer "attended to her emotions" (personal communication, October 8,2008 ). Using empathy to identify with and demonstrate understanding of situations and feelings after reading the negative comments from students can be crucial to the relationship between the faculty developer and the instructor. Simple but powerful phrases such as, "If I'm hearing you correctly," "It sounds as though you're saying," "Do you mean ... " and "I sense that you're feeling ..." can aid communication and give the instructor freedom to explore his or her emotions. Even though most faculty developers use empathic skills in their consultation practices, it does not hurt to review the skills needed to demonstrate active listening while working with a faculty member, particularly one who has received negative feedback and may be processing difficult feelings.

\section{Time}

We observed Jeff, a Mr. Inconceivable-style instructor, multiple times over the course of three semesters. After several semesters of argumentative feedback sessions with Jeff, we had the privilege of observing an a-ha moment as he finally opened up and revealed his fear of judgment from students and his departmental colleagues. He stopped arguing and started asking questions such as, "How do I make my students care?" No doubt the time invested in building a trusting relationship with him contributed 
to Jeff's epiphany. Similarly, Yolanda, a Medea turned Bionic Woman, communicated her desire for more consultation time and follow-up from the faculty developer. Although she made tremendous strides in her teaching, she lost some of her newfound confidence and momentum over time and expressed a need to extend her relationship with her consultant (personal communication, September 26, 2008). All faculty developers undoubtedly know instructors who repeatedly return yet make seemingly few changes to their teaching. Because time is a precious commodity for any faculty developer, perhaps we can all find solace knowing that our investments can pay off.

\section{Resources}

Gloria, an accounting instructor and Bionic Woman, came to a workshop offered through our teaching and learning center. During the session, she asked many questions and took voracious notes. A few weeks later, she popped in to our center, excited to share her success in implementing directed reading strategies she had learned. Likewise, we gave Donald, one of the Mr. Inconceivables profiled here, scholarly articles and current active-learning literature, and eventually he began successfully incorporating ideas from what he perceived to be credible sources. It behooves faculty developers to familiarize themselves with classic teaching and learning literature as well as current SoTL research and make these resources readily available to our instructors. This will not only help us in our day-to-day practice but also solidify our profession as academically respectable.

\section{Relational Perseverance}

To meet the individual needs of instructors, faculty developers must find the best formula combining empathy, time, and resources. Perhaps Scarletts and Medeas, who take criticism personally, will benefit from a greater level of empathy, while Mr. Inconceivables and Neros may respond well to more resources and time. In a nutshell, simply hang in there to find what works to build the best relationship, to wait out the skepticism or indifference, and to offer the best resources for that individual. Persevering and hopefully finding that magical combination of empathy, resources, and time, we have discovered, can help instructors process the feedback in a way meaningful to them. Then maybe a onetime Medea can transition into a Bionic Woman, like Erin or Yolanda; or a Mr. Inconceivable can become a MacGyver, like Donald or Fred. 


\section{What's Gender Got to Do with It?}

Although we found many commonalities among the various response patterns, we also identified some underlying differences along gender lines. Gender differences on the survey questions about the SGID process were not statistically significant, but the content analysis of their opentext responses revealed language-use differences that might speak to the ways these instructors navigated their feedback. In male comments, for instance, we repeatedly saw references to honesty and candidness ("I believe my students were being honest in trying to help me," "I liked them for their honesty," and "I appreciated their willingness to give candid feedback"), whereas female responses uses more emotive language ("I was happy they tried to be constructive," "It was insightful but slightly disappointing," and "I felt somewhat exasperated"). Another difference was the verb tense used. Male instructors consistently used the past tense when describing changes made to their teaching, while female instructors favored the present tense. For example, males gave comments such as, "I increased the time I spent explaining points," while females wrote remarks such as, "I give better directions, slow down, and give more feedback on assignments." If the past tense represents finished action and the present a continuous and dynamic state, this seemingly innocuous tense difference may reveal deeper beliefs about change.

\section{Internal Versus External}

Other responses from our female respondents suggested a more personal and internalized approach to the feedback and change process. Consider the instructors who wrote, "I tried to soften my approach," "Saying I had a four-year-old seems to endear females toward me," or "I really took the feedback to heart." Conversely, among male respondents, the reactions were generally externalized-for example, "slides were criticized and completely reworked," and "I was interested in trying some of the ideas given," or "it has been three years and [he] does not remember" if he made any postconsultation changes. Regardless of whether the feedback received was positive or negative in nature, the female instructors seemed to process it internally, to see it as a memorable reflection on themselves as individuals, whereas the male instructors often viewed feedback as a series of helpful hints or instructions that that they could pick and choose from to improve their teaching. This pattern reflects that identified by Roberts and Nolen-Hoeksema (1989), who found that women responded to performance-related feedback "in a way that indicated that they, more readily than the men, considered the external information, whether 
positive or negative, to have self-evaluative meaning" (p. 741). For instance, although both Scarletts and Neros appear to respond to feedback with apathy, the major difference was in the end result. Some Scarletts shut down and quit, deciding to leave teaching altogether, as Lauren did; whereas Neros could remain unaffected and unconcerned, pursuing the same career regardless of the negative feedback, as Mark did.

\section{Holistic Versus Specific}

Another distinguishing difference between male and female responses was the implicit attitude toward embracing and implementing the feedback. Male respondents exhibited a tendency to make class-specific changes. For instance, in response to the question, "What changes, if any, did you make to your class or your teaching in response to the SGID process?" one male instructor wrote, "I eliminated an extra-credit scenario that many students perceived as being unfair. They were likely a few other minor adjustments that I can't identify presently." Another wrote, "I worked out a system of regular feedback to find out what topics were clearly understood." By contrast, female instructors leaned toward changing their teaching across courses. One female responded to the same question, "I have used more active learning and other class activities"; another wrote, "For valid suggestions about the course's foundation, I was able to change things in future classes." Both the Bionic Women and the MacGyvers reacted to their consultations with energetic action to make positive changes, but the genders differed in the extent to which the instructor incorporated feedback and made changes in overall teaching style.

Being aware of these subtle gender differences (internalization versus externalization of feedback, holistic versus specific approaches to reflective teaching) can prime the faculty developers' expectations of their clients and can help them tailor their consultations to the individual, creating a productive relationship that will foster the positive professional growth of the instructor in need.

\section{Value to Faculty Development}

So how does this research benefit other faculty developers? An overarching theme of all the survey and interview responses was the importance of the consultant-instructor relationship, whether working through diffcult feedback, offering helpful resources, brainstorming new approaches, or just listening. The patterns we have identified may be recognizable to any faculty developer, but being more aware of them can help consultants 
prepare a toolkit of strategies for each individual instructor and build a stronger relationship. Just knowing that one might have to be patient and wait out a Mr. Inconceivable or a Nero, listen to the complaints of a Scarlett, or wipe the tears of a Medea can encourage the faculty developer to persevere. Recognizing gender patterns can help the consultant anticipate the approach an instructor may bring to the consultation. Will she be looking for long-term inspiration? Will he desire an effective, immediate solution to a problem he currently faces in his class? With the proper combination of empathy, time, and resources, a Medea may be a Bionic Woman in waiting, and a Mr. Inconceivable can evolve into a MacGyver.

\section{REFERENCES}

Andersen, K., \& Miller, E. D. (1997). Gender and student evaluations of teaching. PS: Political Science and Politics, 30(2), 216-219.

Bachen, C., McLoughlin, M., \& Garcia, S. (1999). Assessing the role of gender in college students' evaluations of faculty. Communication Education, 48(3), 193-210.

Basow, S. A. (2000). Best and worst professors: Gender patterns in students' choices. Sex Roles, 43(5/6), 407-417.

Brinko, K. T. (1997). The interactions of teaching improvement. In K. T. Brinko \& R. J. Menges (Eds.), Practically speaking: A sourcebook for instructional consultants in higher education (pp. 3-8). Stillwater, OK: New Forums Press.

Centra, J. A., \& Gaubatz, N. B. (2000). Is there gender bias in student evaluations of teaching? Journal of Higher Education, 71(1), 17-33.

Diamond, N. (2002). Small group instructional diagnosis: Tapping student perceptions of teaching. In K. H. Gillespie, L. R. Hilsen, \& E. C. Wadsworth (Eds.), A guide to faculty development: Practical advice, examples, and resources (pp. 83-91). Bolton, MA: Anker.

Franklin, J., \& Theall, M. (1994, April). Student ratings of instruction and sex differences revisited. Paper presented at the 75 th annual meeting of the American Educational Research Association, New Orleans.

Kearney, P., \& Plax, T. G. (1992). Student resistance to control. In V. P. Richmond \& J. C. McCroskey (Eds.), Power in the classroom: Communication, control, and concern (pp. 85-100). Hillsdale, NJ: Erlbaum.

Laube, H., Massoni, K., Sprague, J., \& Ferber, A. (2007). The impact of gender on the evaluation of teaching: What we know and what we can do. NWSA Journal, 17(3), 87-104.

Meyers, S. A. (2003). Strategies to prevent and reduce conflict in college classrooms. College Teaching, 51(3), 94-98. 
Meyers, S. A., Bender, J., Hill, E. K., \& Thomas, S. Y. (2006). How do faculty experience and respond to classroom conflict? International Journal of Teaching and Learning in Higher Education, 18(3), 180-187.

Nasser, F., \& Fresko, B. (2002). Faculty views of student evaluation of college teaching. Assessment and Evaluation in Higher Education, 27(2), 187-198.

Piccinin, S. (1999). How individual consultation affects teaching. In C. Knapper \& S. Piccinin (Eds.), New directions for teaching and learning: No. 79. Using consultants to improve teaching (pp. 71-84). San Francisco: Jossey-Bass.

Piccinin, S., Cristi, C., \& McCoy, M. (1999). The impact of individual consultation on student ratings of teaching. International Journal for Academic Development, 4(2), 75-88.

Pogue, L., \& AhYun, K. (2006). The effect of teacher nonverbal immediacy and credibility on student motivation and affective learning. Communication Education, 55(3), 331-344.

Roberts, T., \& Nolen-Hoeksema, N. (1989). Sex differences in reactions to evaluative feedback. Sex Roles, 21(11/12), 725-747.

Schmelkin, L. P., Spencer, K. J., \& Gellman, E. S. (1997). Faculty perspectives on course and teacher evaluations. Research in Higher Education, 38(5), 575-592.

Sprague, J., \& Massoni, K. (2005). Student evaluations and gendered expectations: What we can't count can hurt us. Sex Roles, 53(11/12), 779-793.

Theall, M. (2005, April). Valid faculty evaluation data: Are there any? An interactive symposium exploring issues in evaluation and student ratings. Paper presented at the 85th annual meeting of the American Educational Research Association, Montreal.

Theall, M., \& Franklin, J. (2001). Looking for bias in all the wrong places: A search for truth or a witch hunt in student ratings of instruction? In M. Theall, P. C. Abrami, \& L. A. Mets (Eds.), New directions for institutional research: No. 109. The student ratings debate: Are they valid? How can we best use them? (pp. 45-56). San Francisco: Jossey-Bass. 